\title{
Identification of problems faced by university libraries in the process of automation: with special reference to the libraries of Moratuwa and Colombo Universities.
}

\author{
T.L. Chrishantha Dilroshan \\ Assistant Secretary \\ University Grants Commission \\ 20, Ward Place \\ Colombo 07, Sri Lanka
}

Tele: +94112693225

\begin{abstract}
The main objective of this study was to identify the problems faced by the University of Moratuwa library and the University of Colombo library in the process of automation. In achieving this objective, the study aimed to identify the software packages used by the two libraries and available modules in them; to find out the availability of infrastructure, hardware and financial facilities in the two libraries; to identify the progress made by two libraries in automation; to identify the attitude of the staff of the two libraries towards library automation; to identify the attitude of the university management towards library automation; to identify the solutions suggest by the two libraries to overcome the problems in automation. Survey method was used to identify the problems and interviews have been conducted with the two librarians and the departmental heads of the two libraries to collect data. The Survey revealed that two libraries surveyed face several problems such as inadequacy of infrastructure and hardware, problems in the software, lack of trained and skilled staff and lack of funds. The study makes recommendations to overcome these problems and achieve successful automation.
\end{abstract}

Keywords: Automation/University Libraries/University of Colombo/University of Moratuwa/ Sri Lanka

\section{Introduction}

\section{History of Library Automation in Sri Lanka}

The Natural Resources, Energy and Science Authority of Sri Lanka (NARESA), currently known as the National Science Foundation (NSF) obtained a computer in 1983 for the use of the Sri Lanka Scientific and Technical Information Centre (SLSTIC). This can be considered as a historical event because this was the first computer set up in a library in Sri Lanka. NSF had to undergo a long process and meet problems to procure this computer due to the attitudes of decision makers, computer scientists and librarians towards the use of computers for library purposes (Yapa, 1998). Although the situation in Sri Lanka was such, during the 1980s, most Western countries automated their libraries rapidly.

UNESCO developed CDS/ISIS by combining its own Computerized Documentation System with the Integrated Set of Information Systems of the International Labour Organization and there had been a rapid progress of library computerization activities in Sri Lanka after the introduction of CDS/ISIS in 1987 (Yapa, 1995). This software was, and is, distributed to libraries free of cost. 


\section{Automation of University Libraries in Sri Lanka}

It was in the year 1986 that the first meeting of university librarians, Vice Chancellors and the then Chairman of University Grants Commission (UGC) was held to discuss any possibilities of automating university libraries (IUCL, 1987).

The Inter University Committee on Librarians (IUCL) emphasized the importance of automating university libraries in order to be on par with the technology development taking place worldwide and brought out issues such as inadequate funds to purchase computers, software and insufficient trained staff etc. In 1991, UGC provided one microcomputer to each of the eight university libraries namely: Peradeniya, Colombo, Moratuwa, Sri Jayawardenapura, Kelaniya, Jaffna, Ruhuna and Open University (Dissanayake, 1995).

UNESCO's freely available database software, "CDS/ ISIS" was used by all the above libraries to enter cataloguing data. In Sri Lanka, as in many countries, CDS/ISIS has been used widely as money has not been available to acquire other software. Since then many library software packages (CDS/ISIS, Purna, LibSys, Lib Suite, Alice and ISURU) have been used by university librarians to automate the functions of the library.

\section{Background of the study}

There are 13 university libraries in Sri Lanka, but with the information gathered before the study, the researcher could identify that there were only few university libraries, which were advanced in the process of automation therefore this study covered only 2 university libraries, namely University of Moratuwa Library (UML) and University of Colombo Library (UCL).

University of Ruhuna Library (URL) was one such library and they were using a software which had been developed by one of the Senior Assistant Librarians. Therefore the situation at URL with regard to automation was unique to that library.

Although the situation at University of Jaffna library was also advanced, there were difficulties in reaching that library to collect data due to prevailing security problems.

The situation at University of Moratuwa Library (UML) was more advanced and University of Colombo Library (UCL) was trying to accelerate their automation activities. Both these libraries were using commercial software for automation. Thus, the library of University of Moratuwa and the main library of University of Colombo were selected for the survey. Branch libraries of the University of Colombo was not surveyed because they were not fully automated.

University of Moratuwa Library (UML) is one of the most prominent technological libraries in the country catering the main subject areas of Engineering, Architecture and Information Technology and other general subjects to fulfill the teaching, learning and research needs of the academic \& non academic staff and the students of the University of Moratuwa, and the Institute of Technology. Furthermore, being a member of information networks in Sri Lanka, UML serves the entire technology community of the country (University of Moratuwa Library, 2005). 

$-98$

University of Colombo Library (UCL), as one of the major research libraries in the country, can be recognized as a significant element in the teaching, leaning and research activities of the university. It provides high quality support for these university endeavours through its resources, extensive use of information and communications technology, and its collaboration with other organizations. University teachers, students, researchers and other staff are able to access exhaustive library resources from their desktops in offices or homes through the advanced information communications network of the library (University of Colombo Library, 2005).

\section{Objectives of the Study}

General objective of this research is to identify the problems faced by University of Moratuwa Library and the University of Colombo Library in automating their functions.

In achieving this objective, the study aims:

- To identify the software packages used by the two libraries and available modules in them;

- To find out the availability of infrastructure, hardware and financial facilities in the two libraries;

- To identify the progress made by two libraries in automation;

- To identify the attitude of the staff of the two libraries towards library automation;

- To identify the attitude of the university management towards library automation;

- To identify the solutions suggest by the two libraries to overcome the problems in automation.

\section{Research Design}

Survey research method was applied for the identification of problems faced by University of Moratuwa Library (UML) and University of Colombo Library (UCL) in the process of library automation.

\section{Population and Sample}

A university library consists of four main departments, namely Acquisition, Technical Services, Reader Services and Periodicals. There are four departmental heads in charge of these four departments. Therefore the librarian and four departmental heads are the persons mainly responsible for the functions of a university library. Thus the librarian and the four departmental heads of UML and UCL were the target population for this study. As the targeted population was not very large, no sampling technique was used for this study. The necessary data was collected from the entire target group.

Table 1 Population / Sample for the Study

\begin{tabular}{|l|c|c|c|}
\hline Library & Librarians & Departmental Heads & Total \\
\hline UML & 01 & 04 & 05 \\
\hline UCL & 01 & 04 & 05 \\
\hline Total & 02 & 08 & 10 \\
\hline
\end{tabular}



$-98$

\section{Research Instrument}

Interview method was used to collect data they are proven to be the best research instrument to be used in this type of research where only a limited number of respondents are involved.

Interviews were conducted in the interviewees' workplace during office hours and it helped the researcher to understand the work situations well. Prior appointments were made with the two librarians and eight departmental heads before conducting interviews, to avoid delays. Two pre-defined interview schedules were used in interviews with the objective of gathering required data and as a guide for the interview; one interview schedule for librarians and the other one for departmental heads. Both these schedules consisted of six main sections as follows:

- General Information

- Information on Automation

- Infrastructure and Hardware Issues

- Software Issues

- Personal and Staff Issues

- Financial and Managerial Issues

Although interview schedules were used, the researcher asked further questions to get clarifications about the answers given by the respondents. All the above techniques allowed the researcher to study in depth the situations, clarify the problems, and obtain a wider range of necessary data in order to identify the problem well.

Since ten persons in two libraries were interviewed, the quantity of data collected was not large and the researcher was able to analyze it manually.

\section{Analysis}

\subsection{General Information}

\section{a. Respondents' Information}

Table 2 illustrates the respondents by their designation. Out of 09 respondents 02 were Librarians, 04 were Senior Assistant Librarians and 03 were Assistant Librarians. Since the post of the head of acquisition department of University of Moratuwa Library (UML) was vacant at the time of the survey, the librarian of that library responded on behalf of that departmental head.

Table 2 Designation of the Respondents

\begin{tabular}{|l|c|c|c|}
\hline Library & Librarians & $\begin{array}{l}\text { Senior Assistant } \\
\text { Librarians }\end{array}$ & Assistant Librarians \\
\hline UML & 01 & - & 03 \\
\hline UCL & 01 & 04 & - \\
\hline Total & 02 & 04 & 03 \\
\hline
\end{tabular}


Sri Lanka Journal of Librarianship and Information Management volume.1, no. 2. pp 82 $-98$

\section{b. Registered Members}

Number of registered members in two libraries are given in Table 3. Accordingly UML has a total of 4052 registered members and UCL has a total of 5000. These include academic, administrative and non academic staff, and post graduate and under graduate students of the two universities.

Table 3 Number of Registered Members

\begin{tabular}{|l|c|}
\hline Library & Number of Registered Members \\
\hline UML & 4052 \\
\hline UCL & 5000 \\
\hline
\end{tabular}

\section{c. Library Collection}

The two librarians were requested to provide information on the strength of the library collection of their libraries. They were asked to give the number of books, periodical titles etc. in their libraries. The results are given in Table 4.

Table 4 Strength of the Library Collection

\begin{tabular}{|l|l|l|l|l|l|l|}
\hline Library & Books & $\begin{array}{l}\text { Periodical } \\
\text { Titles }\end{array}$ & $\begin{array}{l}\text { Reports/ } \\
\text { Thesis }\end{array}$ & $\begin{array}{l}\text { AV } \\
\text { Materials }\end{array}$ & $\begin{array}{l}\text { CD } \\
\text { ROMs }\end{array}$ & Databases \\
\hline UML & 84800 & 200 & 1809 & 280 & 800 & 09 \\
\hline UCL & 430000 & 530 & 650 & 20 & 80 & 10 \\
\hline
\end{tabular}

\section{Progress in Automation}

\section{a. Automation of Library Operations}

Respondents were asked to reply whether their library operations were automated or not. They were further asked whether the automation was at planning, development or operational stages. Table 5 indicates the responses of UCL and UML.

Table 5 Stages of Library Automation in UCL

\begin{tabular}{|l|c|c|c|c|c|c|c|c|}
\hline Stage & \multicolumn{2}{|l|}{$\begin{array}{l}\text { Acquisition } \\
\text { Dept. }\end{array}$} & \multicolumn{2}{l|}{$\begin{array}{l}\text { Technical } \\
\text { Services Dept. }\end{array}$} & $\begin{array}{l}\text { Reader } \\
\text { Services } \\
\text { Dept. }\end{array}$ & \multicolumn{2}{l|}{$\begin{array}{l}\text { Periodicals } \\
\text { Dept. }\end{array}$} \\
\hline & UCL & UML & UCL & UML & UCL & UML & UCL & UML \\
\hline Planning & & & & & $x$ & & & \\
\hline Development & $\mathrm{x}$ & & & & & & $\mathrm{x}$ & \\
\hline Operational & & $\mathrm{x}$ & $\mathrm{x}$ & $\mathrm{x}$ & & $\mathrm{x}$ & & $\mathrm{x}$ \\
\hline
\end{tabular}



$-98$

According to the results Acquisition and Periodicals departments of the UCL were at the development stage in the process of automating their functions. Functions of Technical Services department were in operational stage while the functions of Reader Services department were still in the stage of planning. Functions of all four departments in UML were in operational stage in the process of automation.

\section{Commencement of Automation}

Respondents were asked to mention the year of commencement of automation of their departmental functions. Responses are shown in Table 6.

Table 6 Year of Commencement of Automation of Departmental Functions

\begin{tabular}{|l|c|c|c|c|}
\hline Library & $\begin{array}{l}\text { Acquisition } \\
\text { Dept. }\end{array}$ & $\begin{array}{l}\text { Technical } \\
\text { Services Dept. }\end{array}$ & $\begin{array}{l}\text { Reader } \\
\text { Services } \\
\text { Dept. }\end{array}$ & $\begin{array}{l}\text { Periodicals } \\
\text { Dept. }\end{array}$ \\
\hline UML & 2001 & 1991 & 2001 & 2001 \\
\hline UCL & 2004 & 1994 & 2005 & 2004 \\
\hline
\end{tabular}

\section{Infrastructure and Hardware}

\section{a. Infrastructure Facilities}

Two librarians and departmental heads were asked to state whether they have infrastructure facilities needed for automation. Their replies are given in Table 7.

Table 7 Availability of Infrastructure Facilities

\begin{tabular}{|l|c|c|}
\hline Infrastructure Facility & UML & UCL \\
\hline Uninterrupted Power Supply & Not Available & Not Available \\
\hline Network Facilities for Automated & Available & Available \\
\hline $\begin{array}{l}\text { Furniture needed for } \\
\text { functions }\end{array}$ & Available \\
\hline
\end{tabular}

This table indicates that although both libraries have network facilities and furniture needed for automated functions, both libraries do not have uninterrupted power supply. Although UCL has a generator, it starts to function only after a power failure occurs in the normal power supply. Since some departments lack UPS units they experience the interruption of power supply to their computers.

\section{b. Hardware Facilities}

Table 8 shows the responses received to the question asked about the availability of hardware peripheral facilities to adequate levels.

Table 8 Availability of Adequate Hardware peripheral Facilities

\begin{tabular}{|l|c|c|}
\hline Hardware peripheral & UML & UCL \\
\hline Computers & Inadequate & Inadequate \\
\hline Printers & Inadequate & Inadequate \\
\hline Scanners & Inadequate & Inadequate \\
\hline UPS Units & Inadequate & Inadequate \\
\hline Servers/ File Servers & Adequate & Adequate \\
\hline
\end{tabular}



$-98$

According to the results, both libraries do not have adequate hardware peripheral facilities for automated functions.

\section{c. Hardware Capacity}

Required hardware capacity is necessary for automated functions. But periodicals and technical services departments of UML lack required hardware capacity. However, all four departments in UCL have the required hardware capacity needed for automated functions.

\section{d. Other Infrastructure and Hardware Problems}

The responses given to the question "Do you have any other infrastructure or/and hardware problems?" show that both libraries face a number of problems. The problems they have, can be itemized as follows:

\section{Problems in UML}

- Lack of upgraded and updated computers resulting in slowness of functioning.

- Technical problems in UPS units and printers resulting in mal functioning.

- Slowness of Internet access due to low bandwidth of Internet connection.

\section{Problems in UCL}

- $\quad$ Lack of adequate computers.

- Lack of modern hardware

- Slowness of Internet access due to low bandwidth of Internet connection.

\section{Software Issues}

Software and matters related to software play an important role in the process of automation of library functions. Therefore the researcher paid attention to collect data regarding software issues in the two libraries.

Information received on the software packages used for library automation shows that the UML was using LibSys software and the UCL was using Alice for Windows software.

LIBSYS is a fully integrated multi-user library system incorporating the latest in information technology. LIBSYS, though a powerful system, is easy to operate. The library staff can begin to use it without prior programming or computer skills. It ensures high productivity because of minimal data entry requirements, maximum possible integration of functions and sophisticated search facilities. Built around its own centralized bibliographic database, based on MARC formats, LIBSYS supports all activities relating to acquisition, cataloguing, circulation and serials. Additionally, it provides for analytical indexing of journals, and an advanced user-friendly OPAC interface to access all library materials through a Web browser (LibSys Corporation, Undated).

Alice for Windows is a complete, integrated library and information management system which provides powerful automatic document and resource control. This can be configured to give the most cost-effective method of document and resource management available and can be used to manage a wide variety of materials like 
Sri Lanka Journal of Librarianship and Information Management volume.1, no.2. pp 82 $-98$

journals, books, slides, audio and video cassettes, paper clippings, magazines, charts, maps, equipments, electronic documents, and World Wide Web sites.

Alice performs all the tasks needed to manage a library. These can be divided into three broad activities:

- Recording of items

- Finding items

- Controlling the use of items

Modules in Alice are grouped into three sets: Standard modules, Advanced modules and Special modules (Softlink Asia Pvt. Ltd., Undated). Modules available in the software packages are indicated in Table 9.

Table 9 Availability of Modules in Software Packages

\begin{tabular}{|l|l|l|}
\hline Modules & LibSys & Alice \\
\hline Acquisition & Available & Available \\
\hline Cataloguing & Available & Available \\
\hline Circulation & Available & Available \\
\hline Serials Control & Available & Available \\
\hline OPAC & Available & Available \\
\hline
\end{tabular}

\section{a. Suitability of Software}

All respondents of UML mentioned that the software they were using (LibSys) was suitable for automation of functions in their departments and functions in the library as a whole.

This was different at UCL. One respondent (head of periodicals) of UCL said that the software they were using (Alice) was not fully suitable for the automation of functions in that department. Other respondents were of the view that the software they were using (Alice) was suitable for automation of functions in their departments.

\section{b. Cost and Maintenance Cost of the Software}

Librarian of the UML mentioned that the cost of the software (LibSys) was high but the maintenance cost of the software was not high. The cost of the LibSys software was two million rupees.

On the other hand the librarian of the UCL was of the view that the cost of the software (Alice) was affordable and the maintenance cost of it, was also standard. The cost of the Alice software was six hundred thousand rupees. 

$-98$

\section{c. User Friendliness of the Software}

Respondents were asked whether the software they were using was user friendly or not. All respondents of UML said that the software they were using was user friendly. Two respondents of UCL mentioned that the user friendliness of their software was on a satisfactory level, while another two were of the view that the software was not so user friendly. One respondent said that the software was not user friendly.

\section{d. Limitation in Number of Records}

As an answer to the question asked on maximum number of records that the software could accommodate, both librarians replied that there was no limitation in maximum number of records.

\section{e. Facility for Sinhala/ Tamil Fonts}

Both librarians replied that both software packages (LibSys \& Alice) do not have facilities to enter data using Sinhala/ Tamil fonts and search Sinhala/ Tamil keywords.

\section{f. Manuals provided with the Software}

Respondents were asked whether there was a difficulty in understanding the manuals provided with the software. Although all respondents of UML replied that there was no difficulty in understanding the manuals provided, one respondent mentioned that vendor was not providing updated manuals.

The responses received from UCL were diverse. Two respondents said that there was no difficulty in understanding such manuals. But the other three expressed the idea that there was a difficulty in understanding the manuals provided.

\section{g. Training and vendor support}

According to the responses to the questionnaire, it was clear that both libraries were provided with software training by the vendors of the packages. Both librarians were asked whether they obtain after sale support from vendors of the software. The answers revealed though UML gets vendor's after sale support, UCL gets very little.

At the same time all respondents were asked whether they get vendors' immediate support when there is a problem or breakdown. While four respondents of UML said that they get vendor's immediate support one said such immediate support was not received always.

While only one respondent of UCL said that they get vendor's immediate support, others mentioned that they do not. Further, they said that local agent's support was not satisfactory.

\section{h. Updating the Software}

Answers given by the two librarians revealed that the vendors of both software (LibSys \& Alice) packages update the software to suite the developments of the technology. 

$-98$

\section{i. Other Software Problems}

Respondents were asked to mention any other software problems they have and they came up with a number of problems.

\section{Problems in UML}

Librarian of the UML replied that they get few problems after installing updated versions of the software. At the same time, the Head of the Reader Services Department said that they have difficulty to customize the software to suite the needs of their department. Head of the Periodicals Department was of the opinion that they have some problems in sending reminders to periodical vendors through the system. Head of the Technical Services Department mentioned that they face difficulties in printing catalogue cards, spine labels and barcode labels through the system since the software supports well only for Windows 98 operating system in printing above mentioned cards and labels. Head of the Acquisition Department replied that they have no other software problems.

\section{Problems in UCL}

Head of the Acquisition Department mentioned that they have problems in entering currency figures and they do not get warning messages when there is a duplication of records. According to the Head of Reader Services Department, report generation and retrieval were slow and it was a difficulty for them. Other respondents of the UCL said that they do not face any other problems in the software.

\section{Personal and Staff Issues}

\section{a. Sufficient Staff}

Responses revealed that Technical Services and Periodicals Departments of UML did not have sufficient staff for automated functions. The other two departments had sufficient staff.

Periodicals Department of the UCL lack staff for automated functions. At the same time, in general, library lacks computer technical staff such as Instructors, Network Administrators and Computer Application Assistants.

\section{b. Trained and Skilled Staff}

Respondents were asked whether they have trained and skilled staff in using computers in general. The replies showed that UML has trained and skilled staff while the UCL has not.

\section{c. Working Knowledge}

The answers given to the question "Does your staff have a good working knowledge of the software and hardware used for library automation?" revealed that staff of UML had a good working knowledge of the software and hardware used for library automation, while part of the staff of the UCL had that knowledge. 

$-98$

\section{d. Person in-charge of Automation}

According to the survey both libraries had a person in-charge of library automation. In UCL a Senior Assistant Librarian and in UML an Assistant Librarian were working in this capacity.

\section{e. Training Opportunities}

Respondents were asked whether their staff have opportunities for training on computer technology. The replies revealed that although all respondents of UCL said that they have training opportunities, two of them differed in their view.

While three of the respondents of UML said that their staff has training opportunities other two said that such opportunities were inadequate.

\section{f. Attitude of the Staff}

According to the responses given by the two librarians, they as well as the other executive staff of the two libraries were positive towards library automation.

\section{g. Future of Computers and Library Staff}

Respondents were asked whether they think that in future computers will replace some library staff. Four respondents of UML were of the view that computers would not replace library staff. One said that computers would replace some library staff.

All respondents of UCL replied that computers would not replace library staff.

\section{h. Any other Personal or Staff Problems}

Respondents were asked to mention any other personal or staff problems, which affect library automation. According to the responses UML had the following problems:

- $\quad$ Lack of training for staff on updated versions of the software.

- $\quad$ Lack of training for staff on e-mail and Internet.

- Transfers/ resignation of trained staff.

- Fear of staff to face challenges and take responsibilities

UCL had following problems:

- $\quad$ Shortage of computer technical staff.

- $\quad$ Lack of training in modern information services.

\section{Managerial and Financial Issues}

\section{a. Attitude of the University Management}

Both librarians replied that the attitude of the top management of both universities was positive and that they are support in automation of their libraries. 

$-98$

\section{b. IT Budget}

The two librarians were asked whether they have an annual IT budget for their library. Librarian of UML said that they had an IT budget only in 2004 and 2005. Librarian of UCL said that the UGC has been giving them a separate IT budget during the last 3 years (2003-2005).

\section{c. Funds for Infrastructure and Hardware}

Respondents were asked to mention whether they have enough funds to obtain infrastructure and hardware necessary for library automation. Three respondents of UML said that they have enough funds while two said that they do not have. In the same way, two respondents of UCL said that they have enough funds while the other three said they do not have enough funds.

\section{d. Funds for Software}

The two librarians were asked whether they have enough funds for software and maintenance of the software. Here, while the librarian of UML replied that they have enough funds, the librarian of UCL replied that they do not have enough funds.

\section{e. Funds for Training}

According to the replies given by both librarians to the question "Do you have enough funds to provide necessary training for the staff on available software and computer technology?", it was obvious that both libraries do not have enough funds for such training.

\section{f. Any other Financial and Managerial Problems}

All respondents were asked to mention any other financial and managerial problems they face. The replies revealed that both libraries do not have any other financial and managerial problems.

\section{Most Often Encountered Problems}

All respondents were asked to mention problems that were most often encountered in using computers in their libraries and departments. The results of the survey showed that both libraries had such problems.

Most often encountered problems in using computers in UML

- Power failures causing interruption

- Outdated computers and printers

- Difficulties in customizing the software

- Difficulties in training the staff

Most often encountered problems in using computers in UCL

- Slowness of Internet access due to low bandwidth

- Network breakdowns

- Outdated computers

- Untrained and incapable staff 

$-98$

\section{Any other Problems}

Respondents were asked to mention if there were any other problems which affect library automation. All of them were of the idea that they do not have problems other than the problems they gave above, which affect library automation.

\section{Suggestions to Overcome the Problems}

Finally all respondents were given a chance to give their suggestions to overcome the problems they face in automating their library functions.

The suggestions given by the respondents of UML can be listed as follows:

- Installing of a generator for uninterrupted power supply

- Replace outdated computers and other equipment with updated items

- Provide necessary training for library staff

- Get vendor support to customize the software according to the needs of the library

- Formation of a team in the library to monitor and evaluate the automation project at different stages and propose developments

- Create a cadre position for a system administrator to handle the automated system and to be responsible for its operations

The suggestions given by the respondents of $\mathrm{UCL}$

- Create cadre positions for network administrators and computer application assistants

- Recruit technically competent staff to accelerate the automation activities

- Provide necessary training for existing library staff

- Increase the bandwidth of the Internet connection

- Obtain new equipment needed for automation.

\section{Conclusions and Recommendations}

This study was focused on identifying the problems faced by UML and UCL in the process of automation. In identifying such problems the researcher fully comprehended the status quo in the two libraries and could arrive at following conclusions;

- The progress in automation is very slow. Both libraries have taken a long period of time to automate their library functions.

- Both libraries lack infrastructure and hardware facilities required for a smooth running of an automated system.

- Low bandwidth of Internet connection creates problems in accessing Internet in both libraries.

- Although cost of Alice software is affordable, the cost of LibSys software is high. 
Sri Lanka Journal of Librarianship and Information Management volume.1, no.2. pp 82 $-98$

- Although both libraries are using two advanced commercial software packages, they face a number of software problems.

- The local agent for the Alice software is not providing an effective and a satisfactory service.

- Both software packages (LibSys and Alice) do not have the facility to use Sinhala and Tamil fonts to enter data and search key words.

- Although UML has sufficient skilled and trained staff, UCL lacks such skilled and trained staff needed for automation and they are in need of computer technical staff such as Network Administrators and Computer Application Assistants.

- Library staff does not have adequate opportunities for training on computer technology.

- In general, both libraries do not have access to sufficient funds to obtain necessary infrastructure and hardware needed for improved, constantly updating automation.

- Although UML has funds for software UCL does not.

- Both libraries lack funds to provide necessary on going training for staff on available software and computer technology.

- The attitude of the librarians, executive staff and other library staff towards library automation is positive. Suggestions to overcome the problems faced by the two libraries in the automation process have been forthcoming. Thus it is evident that they want to move forward in automation.

- The attitude of the top management of the two universities towards library automation is also positive and they give their support for library automation.

University libraries have to play a leading role to maintain their position as the university's principal information resource and service provider. The challenges faced by university librarians are two fold. First is to automate their library operations and develop the capacity to deal with large quantities of information in a variety of new electronic formats; and second is to continue to strengthen and provide for the growth of their traditional collections and services and for automation to keep pace with increased resources (Dissanayake, 1995). Automating a library is only the first step. Keeping up with new trends in information and communication technology is also of paramount importance. If the libraries fail to meet these challenges successfully the tremendous investment that universities have made in their library collections and facilities will be seriously undermined. 

$-98$

\section{Recommendations}

- Appoint an IT committee in each university library including both library and computer staff to deal with automation activities. This committee should regularly review the progress and propose developments. This can overcome the slowness in the process of full automation and updating.

- Formulation of a special committee of university librarians for library automation project. This committee can discuss problems and obstacles and find solutions; persuade the UGC or higher management to provide adequate funds needed for automation of libraries and for the maintenance of automated libraries. This will meet the problems of lack of infrastructure, hardware and lack of funds for infrastructure, hardware, software and training for staff.

- It is recommended that each library should formulate a proper written down policy on library automation. It should identify appropriate hardware, software and manpower; it should specify long and short-term targets in automation. This policy will help each library to select suitable hardware and software after evaluating the hardware and software used in other libraries. This can be a solution for the problems and shortcomings in the existing software and hardware. This policy should be reviewed and updated at least every two years.

- It is recommended to develop and provide training opportunities suitable to train library staff on the use of computers, specially on the use of existing software and hardware with adequate practical experience. These training opportunities will help to overcome the problem of insufficient skilled and trained staff and inadequacy for training opportunities. Training should be continuous.

- Take steps to encourage computer centers at the Sri Lankan universities and the national organizations involved in library development and utilization of information technology to develop indigenous software packages to suit local library needs. They can find solutions for the nonavailability of the facility to use Sinhala and Tamil fonts and this can overcome the problem of unsatisfactory service from local software agents. 
Sri Lanka Journal of Librarianship and Information Management volume.1, no.2. pp 82 $-98$

\section{References}

Dissanayake, B.G. (1995). A study on automation of university libraries in Sri Lanka. Unpublished MLS thesis. University of Colombo.

Inter University Committee on Librarians (1987). Report on computerization of university libraries in Sri Lanka. Unpublished report submitted to University Grants Commission by inter university librarians.

LibSys Corporation (Undated). LibSys [a booklet]. LibSys Corporation, New Delhi.

Softlink Asia Pvt. Ltd. (Undated). Alice for windows [a booklet]. Softlink Asia Pvt. Ltd., New Delhi.

University of Colombo, Library (2005). [On-line], Available:

http://www.lib.cmb.ac.lk/about.htm [2005, Oct. 20].

University of Moratuwa, Library (2005). [On-line], Available:

http://www.lib.mrt.ac.Ik/about/about.html\#Introduction [2005, Oct. 21].

Yapa, N.U. (1995). Impact of the micro CDS/ISIS in library automation in Sri Lanka. Sri Lanka Library Review, 9(1/2), pp. 4.

Yapa, N.U. (1998). Usage of software in Sri Lankan libraries, Library News, 18 (2), pp.11-15, 24.

\section{Acknowledgement}

Co-operation extended by the Librarians, Senior Assistant Librarians, Assistant Librarians and other staff of the two university libraries during the data collection is gratefully acknowledged by the author. 